\title{
Contribution of acoustic emission to the understanding of Sulfide Stress Cracking of low alloy steels
}

\author{
Véronique Smanio $^{\mathrm{a}, \mathrm{b}}$, Marion Fregonese ${ }^{\mathrm{c}}$, Jean Kittel ${ }^{\mathrm{a}}$, Thierry Cassagne ${ }^{\mathrm{b}}$, François Ropital ${ }^{\mathrm{a}}$, \\ Bernard Normand $^{\mathrm{c}}$
}

${ }^{a}$ IFPEN, Rond-point de l'échangeur de Solaize, BP3 - 69360 Solaize - France

${ }^{\mathrm{b}}$ TOTAL, ave Larribau - 64018 Pau Cedex - France

${ }^{\mathrm{c}}$ INSA-Lyon, MATEIS UMR5510, 21 av J. Capelle - 69621 Villeurbanne Cedex- France

Corresponding author: marion.fregonese@insa-lyon.fr

\section{ABSTRACT}

The Acoustic Emission technique was applied to standard tests devoted to evaluate sulfide stress cracking susceptibility of steels for oil and gas industry. The mapping of the density of AE signals vs. their location on the specimen gauge length as a function of time allowed early detection of cracking, and gave meaningful information on incubation times and propagation rates. Sulfide stress cracking initiation was correlated with the presence of critical surface defects. A mechanism involving plastic strain and/or metal dissolution was proposed to account for crack propagation.

\section{INTRODUCTION}

Hydrogen embrittlement (HE) of steels in $\mathrm{H}_{2} \mathrm{~S}$ media is a major issue in the oil and gas industry. This type of damage can lead to the failure of important production equipment.

Several kinds of damage may be caused by $\mathrm{H}_{2} \mathrm{~S}$ in contact with low alloy steels [1]. One of the main cracking processes is Hydrogen Induced Cracking (HIC), which is caused by the accumulation of hydrogen at internal traps, such as non-metallic inclusions, regions of anomalous microstructure produced by the segregation of impurities and alloying elements, and other weak interfaces (e.g. the boundary between pearlitic and ferritic phases). When hydrogen concentration reaches a critical value at the defect, recombination to gaseous hydrogen occurs, with the corresponding build-up of high pressure gas leading to internal 
cracking. Under conditions of applied or residual tensile stresses, HIC cracks can become aligned in the through thickness direction resulting in 'ladder like' crack arrays referred to as Stress Oriented Hydrogen Induced Cracking (SOHIC). This phenomenon is usually associated with low-strength welded ferritic pipe and pressure vessel steels.

The present work is focused on a third kind of wet $\mathrm{H}_{2} \mathrm{~S}$ cracking mode: Sulfide Stress Cracking (SSC). SSC leads to early failure of the metal due to the combined effect of both hydrogen penetration and tensile stress (residual and/or applied). Crack initiation of SSC always occurs on the surface. High strength metallic materials and hard welded zones are prone to SSC. Although the mechanisms proposed to account for HIC and SOHIC are generally well accepted, the SSC mechanism is still controversial, with several models proposed in the literature. A model based on the reduction of cohesive forces induced by hydrogen was introduced by Troiano [2] and further developed by Oriani [3]. Hydrogen insertion in solid solution would decrease the forces required to fracture the metal along the crystal lattice i.e. decrease cohesion forces of the lattice and the energy necessary to induce cleavage, in particular at defects and interfaces. Other models are based on hydrogen induced local plasticity. Beachem [4] proposed that hydrogen absorbed at the crack tip enhances dislocation glide and therefore plastic strain processes leading to metal fracture. In the hydrogen enhanced localized plasticity (HELP) model, hydrogen increases dislocation mobility. Dislocations can then pile-up more easily, resulting in a distribution of microscopic highly strained areas surrounded by less ductile areas. Fracture is then micro-ductile, with a brittle appearance [5]. Similarly, Lynch [6] proposed the weakening of interatomic bonds by hydrogen adsorption at the crack tip. Localized plastic strain would then lead to the formation of microvoids ahead of the crack tip. Consequently, crack propagation would occur by microvoid coalescence.

In $\mathrm{H}_{2} \mathrm{~S}$ environment, Crolet [7] proposed a high energy process where proton absorption into the metal induces a dilatation of the crystalline lattice and a local increase of triaxial stress within the first surface layers. The applied stress would then induce SSC initiation and propagation. Moreover, proton absorption within the metal would be enhanced by $\mathrm{H}_{2} \mathrm{~S}$ itself via the formation of adsorbed $\mathrm{HS}^{-}$on the metallic surface. On the other hand, in the presence of $\mathrm{H}_{2} \mathrm{~S}$, a scale of iron sulfide is formed on the surface of the steel. The first stage of iron sulfide formation consists in the nucleation and growth of mackinawite that can be considered as stoechiometric FeS [8]. In longer term exposures, a multi-stage film growth mechanism is involved where mackinawite forms and ruptures. Then, depending on the exposure time, the temperature, the $\mathrm{H}_{2} \mathrm{~S}$ and the chloride contents, the pyrrhotite and pyrite forms of iron sulfide 
can grow. Mackinawite was demonstrated to be non protective towards corrosion [9][10] or even suspected to promote corrosion, in incorporating $\mathrm{FeSH}^{+}$ads ion as: $\mathrm{FeSH}^{+}$ads $\rightarrow \mathrm{FeS}+\mathrm{H}^{+}$. $\mathrm{FeSH}^{+}$ads formation results from sequential chemisorption followed by anodic discharge: $\mathrm{Fe}+$ $\mathrm{H}_{2} \mathrm{~S} \rightarrow \mathrm{FeSH}_{\text {ads }}^{-}+\mathrm{H}^{+}$then $\mathrm{FeSH}_{\text {ads }}^{-} \rightarrow \mathrm{FeSH}^{+}$ads $+2 \mathrm{e}^{-}$. [11]. $\mathrm{FeSH}_{\text {ads }}^{+}$can also suffer hydrolysis liberating $\mathrm{Fe}^{2+}: \mathrm{FeSH}^{+}$ads $+\mathrm{H}^{+} \rightarrow \mathrm{Fe}^{2+}+\mathrm{H}_{2} \mathrm{~S}$.

$\mathrm{H}_{2} \mathrm{~S}$ induced damage evaluation usually consists of ex situ examination of fractured specimens after standard tests. However, this methodology is often insufficient to identify and deeply study the different steps of crack propagation, particularly in the case of SSC. Therefore, the use of an in-situ evaluation method appears to be an interesting development. Among the possible in-situ methods, acoustic emission (AE) exhibits interesting potentialities for corrosion study and monitoring. Indeed, the detection possibility was established and good correlations were obtained between specific AE parameters and the amplitude of corrosion damage in various cases: stress corrosion cracking [12-15], abrasion or erosion corrosion [16], pitting corrosion [17-24], crevice corrosion [25-27], exfoliation corrosion [28], uniform "acidic" corrosion [17][29-30], and also to monitor cracking in sour media [31-36]. Weng et al. [31] found a correlation between HIC damage evaluated by Crack Length Ratio (CLR) [37] and the AE cumulative energy level. Cayard et al. [32] and also Gingell et al. [33] showed that during sour exposure tests under stress, a higher amount of cumulative $\mathrm{AE}$ energy was recorded for the experiments leading to fracture compared to non-failure tests. This critical energy build-up associated with specimen failure remains dependent on the steel tested and on the applied stress level. They also showed that AE could be used to discriminate between the initiation and propagation stages of SOHIC.

As far as AE detection of SSC is concerned, most of the published works [34-36] are based on monitoring during standard SSC tests described in NACE TM0177-96 [38]. From these studies, AE appears to be a powerful tool for monitoring $\mathrm{H}_{2} \mathrm{~S}$ cracking. Some correlations between the AE energy and the extent of cracking were found. However, for most of the past studies, the cracking process was not always clearly identified or documented, especially for SOHIC and SSC, which were not systematically differentiated. Furthermore, the AE signals associated to the cracking process itself were not discriminated. Considering this last point, a step forward was recently reported by the authors [39-40]. Indeed, the AE contributions from $\mathrm{H}_{2}$ evolution due to acid corrosion, FeS layer build-up, and cracking, all constituting AE sources, were separated by identifying the acoustic signature of each process. This discrimination was performed by isolating physically the active sources through specific 
electrochemical polarization procedures. The characteristics of the corresponding AE signals were identified. The most discriminating representation was obtained by plotting absolute energy of the signals as a function of their duration (Figure 1). On this correlation chart, it was possible to separate AE events related to HIC from those related to the corrosion reactions, allowing a better analysis of cracking associated signals. However, this discriminating analysis demonstrated that SSC development led to the emission of AE signals that could not be directly identified on the same energy-duration correlation chart [39]. For that particular process of HE, a specific analysis giving the evolution of the density of AE signals vs. their location and the time of test was necessary.

In that context, the aim of the present work is to validate this new discriminating $\mathrm{AE}$ analysis of SSC, and to establish its performance for better understanding and evaluation of this particular $\mathrm{H}_{2} \mathrm{~S}$ induced cracking process.

\section{EXPERIMENTAL PROCEDURE}

\section{Material}

This study was conducted on a C110 steel grade usually used as well tubing material. The chemical composition of the steel was analyzed by optical emission spectroscopy (OES), except for carbon and sulfur, analyzed by a chemical method (Table 1). The C110 grade contains alloying elements, such as chromium and molybdenum, providing a good resistance to hydrogen embrittlement. Tensile properties of the steel in the longitudinal direction are given in Table 2. The microstructure of $\mathrm{C} 110$ grade is a tempered martensite with macrosegregation. This microstructure is usually resistant to HIC [41]. Two surface states were studied: i/ mechanical polishing as recommended in NACE TM0177-96 standard (final surface roughness below $0.81 \mu \mathrm{m}$ ) [38] and ii/ electrochemical polishing in $42 \%$ vol. phosphoric acid and $34 \%$ vol. sulphuric acid at $1 \mathrm{~A}$ for $30 \mathrm{~min}$. In this latter case, diameter of the as-machined samples was reduced by $0.8 \%$.

\section{Experimental set up}

The experimental set up (Figure 2) was based on the standard tensile test described in NACE TM0177-96 (method A) [38]. Constant load was applied with the proof ring. NACE standard specimens were adapted to allow positioning two AE sensors at the bottom of the specimen. The geometry of the gauge section of the standard specimen was unchanged (length $=25.4$ 
$\mathrm{mm}$, diameter $=6.35 \mathrm{~mm}$ ). During the test, only this section was immersed in the corrosive solution. Tests were conducted in buffered solution according to EFC 16 [42] (50 mg/L NaCl and $4 \mathrm{mg} / \mathrm{L} \mathrm{CH}_{3} \mathrm{COONa}$ in distilled water) and under 1 bar $\mathrm{H}_{2} \mathrm{~S}$. De-aeration of the solution was performed by nitrogen bubbling ensuring less than $15 \mathrm{ppb}$ by weight dissolved oxygen before $\mathrm{H}_{2} \mathrm{~S}$ introduction. The corrosive fluid (sour media) was circulated between the test cell and a separate glass vessel, in which $\mathrm{H}_{2} \mathrm{~S}$ bubbling was maintained. This procedure avoided any interfering $\mathrm{AE}$ noise detection (e.g. gas bubbling in the test cell would result in $\mathrm{AE}$ ) and to maintain constant electrochemical conditions in the cell during the test (easier $\mathrm{pH}$ control). The $\mathrm{pH}$ was measured with a $\mathrm{pH}$ meter located in this glass vessel and buffered every day by $\mathrm{HCl}$ or $\mathrm{NaOH}$ additions.

$\mathrm{AE}$ instrumentation consisted of a transducer, a preamplifier and an acquisition device (MISTRAS with AEWIN software from Physical Acoustic Corp.). The gain of the preamplifier was set to $40 \mathrm{~dB}$. A band pass filter with frequency range from 100 to $400 \mathrm{kHz}$ was used. In this study, the threshold was set to $28 \mathrm{~dB}$. The transducers were Nano 30 type from PAC (piezo-electric disks). For each detected AE signal, several acoustic parameters were calculated and recorded, e.g. event amplitude, duration and energy. For each AE signal, the location of source on the specimen was determined by measuring the delay of event detection time between the two sensors. Spatial and temporal post-filtering treatments were also made on the AE data. Only the AE signals located on the gauge section and detected before failure are taken into account for the analysis. The analysis of $\mathrm{AE}$ data was first performed according to previous works [39], allowing identifying three typical sources: i/ $\mathrm{HIC}$, ii/ $\mathrm{H}_{2}$ evolution at the steel surface, iii/ FeS build-up (see Figure 1). In a second configuration, another procedure was applied by using source location. Because the two sensors were placed at either extremity of the specimen, it was possible to determine the position of the source for each AE signal detected on both sensors. This was achieved by comparing the times at which an identical AE signal was detected on each sensor. Then, knowing the distance between both sensors, the position of sources is obtained. Using $\mathrm{AE}$ source position as additional parameter, the analysis of AE data consisted in mapping the density of AE signals as a function of position on the gauge section of the specimen and as a function of the time during the test.

\section{RESULTS}


Table 3 summarises the different sets of experimental conditions and the observed times to failure. Condition 1 consists of $\mathrm{H}_{2} \mathrm{~S}$ exposure without applied load. Therefore, no $\mathrm{SSC}$ is expected. The goal of this test is to validate that the tested steel is not sensitive to HIC. Conditions 2 and 3 consist of $90 \%$ YS strained specimens exposed to $\mathrm{H}_{2} \mathrm{~S}$, with two distinct surface preparations. Corresponding AE results, plotted on absolute energy vs duration correlation charts are shown on Figures $3 \mathrm{a}, 3 \mathrm{~b}$ and $3 \mathrm{c}$ for conditions 1, 2 and 3 respectively. According to previous results [39], analysis of AE data for condition 1 (Figure 3a) suggests that the only active $\mathrm{AE}$ sources are hydrogen evolution and the FeS layer. Both metallographic examination and ultrasonic analysis of the specimens confirmed the absence of HIC phenomena. For condition 2 (Figure 3b), when a constant load is applied on an electropolished specimen, no failure was obtained after $800 \mathrm{~h}$ testing and no crack was detected by metallographic examination. AE results are in agreement with these observations: according to previous results [39], only populations of AE signals associated with $\mathrm{H}_{2}$ and $\mathrm{FeS}$ are identified on the correlation chart. For condition 3 (Figure 3c), all of the mechanically polished specimens failed. Times to failure varied between 64 and 200 hours (Table 4). Figure 4a shows a typical fracture surface observed by SEM. Two areas can be identified. Fracture seems to be initiated on the surface of the sample perpendicular to the loading direction (area 1). A brittle type transgranular fracture is observed in area 1, (Figure 5) while microvoids typical of a ductile failure are identified only in area 2 (Figure 6). A profile of the fracture surface along the line drawn on Figure $4 \mathrm{a}$ can be extracted from a $3 \mathrm{D}$ reconstruction of the surface using a 3D microscope (Figure 4b). Area 1 which is brittle-like corresponds to a flat surface perpendicular to the direction of applied load. Area 2, identified as ductile, corresponds to the $45^{\circ}$ region. This profile is typical of a SSC rupture: initial hydrogen assisted crack corresponds to the $90^{\circ}$ brittle area. Then, as the cross-sectional area of the loaded part is reduced, the applied stress reaches the UTS and the sample fails by $45^{\circ}$ ductile fracture. Corresponding AE results are plotted in the energy vs. duration plane on Figure 3c. In this correlation chart, we cannot distinguish any new population of signal which would correspond to SSC. Either there is no specific acoustic emission related to SSC, or the corresponding signals do not differ from $\mathrm{H}_{2}$ and $\mathrm{FeS}$ signals by energy and duration characteristics. This result is in agreement with previous results providing evidence that SSC signals can not be discriminated from $\mathrm{H}_{2}$ and $\mathrm{FeS}$ signals on absolute energy-duration correlation charts [39]. Therefore, other approaches were tested to extract AE information related to SSC. The best results were obtained by mapping the density of AE signals as a function of position on the gauge section of the specimen and of the time of the test (Figure 
7). The density of AE signals is quite homogeneous on the whole gauge length, except in well defined zones where it is higher for a certain period of time. The direct reading of this figure indicates that an AE activity well above the background level was detected at some location and after a certain time. More remarkably, such intense AE activity was always found at the position corresponding to the final failure. Surface examination was also performed at other areas where high AE activity was found, and crack initiation was detected (Figure 8). It could therefore be concluded that these high density signals could be associated with SSC initiation, as previously demonstrated [39].

In order to obtain time and energy information on $\mathrm{AE}$ signals associated with $\mathrm{SSC}$, characteristics of AE signals located on the final rupture area (zone 1 on Figure 9) are compared with those of signals located just above the final rupture area, where neither cracking nor increase in AE signals density were detected (zone 2 on Figure 9). Both zones have a surface area of $60 \mathrm{~mm}^{2}$. For each zone, both number and energy of AE signals are plotted versus time (Figure 10). During the first part of the test, signals recorded on both areas (zone 1 and zone 2) exhibit the same evolution. From the start of the test to $370 \mathrm{ks}$, the same cumulative AE activity is recorded for both areas of the specimen. However, from $370 \mathrm{ks}$ until final fracture, the number and energy of AE signals increase drastically on the area of the specimen corresponding to the final fracture (zone 1). At the same time, AE activity of the other area continued to increase at the same rate (zone 2). At the end of the test, $2.5 \times 10^{4}$ signals have been recorded on zone 2 with a cumulative energy of $510^{5}$ aJ, with a constant increase, compared to $10^{5}$ signals and $8.2 \times 10^{5}$ aJ on zone 1 , where the final rupture is located, with a sharp increase of both parameters when SSC initiates. Comparing the evolution of signals recorded on both areas, it can be assessed that a signal related to hydrogen or FeS layer evolution (the only signal type that is detected on zone 2) carries an average energy of $20 \mathrm{aJ}$, whereas a signal associated to SSC development (detected on zone 1, together with $\mathrm{H}_{2}$ and $\mathrm{FeS}$ layer evolution signals after SSC initiation) carries an average energy that is 5 times lower ((8.2-5):(1-0.25), see Figure 10). SSC propagation is therefore associated with a sharp increase in AE signals density, but SSC associated AE signals have low energies.

From the representation of the location of the density of detected AE signals on the gauge length of the specimen versus the time of test (Figure 7), it is also possible to define the SSC incubation time as the time before signals density increases locally, together with the propagation time of the cracks until final failure. On the other hand, the observation of the brittle areas on the fracture surfaces of the failed specimens (Figure 5) allows measuring the 
SSC depth and therefore calculating the SSC propagation rate. SSC propagation rates that can be evaluated with this methodology exhibit good reproducibility: $2 \times 10^{-8} \pm 0.5 \times 10^{-8} \mathrm{~m} \cdot \mathrm{s}^{-1}$. From the representation of the location of the density of detected AE signals on the gauge length of the specimen versus time (Figure 7), it is also possible to define the SSC incubation time as the time before signal density increases locally, together with the propagation time of the cracks until final failure.

\section{DISCUSSION}

The present results demonstrate that the steel grade studied here is not prone to HIC when tested without external stress. Metallographic examination, as well as ultrasonic scans showed the absence of internal cracks, in agreement with AE signals analysis: no HIC associated AE signals were detected in any experiments. Both the tempered martensite microstructure and chemical composition of $\mathrm{C} 110$ grade can account for its good HIC resistance [41]. When C110 specimens were tested under $90 \% \mathrm{YS}$ applied load at $\mathrm{pH} 3.5$ under 1 bar $\mathrm{H}_{2} \mathrm{~S}$, most experiments led to SSC fracture. Acoustic Emission analysis consisted first to apply a methodology that gave excellent results in HIC analysis [39-40]. For all SSC experiments, no AE data typical of HIC were detected. This is a clear confirmation that SSC and HIC proceed by different mechanisms. However, another type of analysis of AE data proved the ability of the AE technique to detect differences between failed and non failed experiments. Also, the representation of the density of detected AE signals on the gauge length of the specimen versus the time of test (Figure 7) allowed locating the initiation sites and the final failure zone tens of hours before failure. Early detection of SSC by AE was therefore confirmed to be possible. More detailed analysis of AE signals associated with SSC revealed that most of them seem to have a low energy compared to $\mathrm{H}_{2}$, FeS and HIC AE signals [40]. When HIC propagation occurred, high AE energy jumps associated with decohesion of interfaces exhibiting cleavage features were observed. From the present AE results, it was therefore confirmed that SSC does not initiate as sub-surface HIC, which is now well recognized. Surface preparation of the specimen had an impact on SSC. Electropolishing provided a higher resistance to SSC vs. mechanical polishing performed as recommended by NACE TM0177-96 [38]. Indeed, for all electropolished specimens, no fracture was observed after more than $720 \mathrm{~h}$. testing. Furthermore, no evidence of SSC initiation was detected by acoustic emission, and no crack was observed at the surface of the specimen by optical microscope 
observation. On the other hand, all mechanically polished specimens failed. Fracture surface analysis confirmed that cracking occurred through a SSC rather than a SOHIC mechanism. Therefore, surface preparation appears to be a first order factor for SSC initiation.

\section{SSC initiation:}

At the beginning of exposure tests, homogeneous $\mathrm{AE}$ data was recorded on the whole specimen surface. This AE activity could be linked with a randomly distributed localised corrosion. Indeed, cross section observations of specimen areas exhibiting a high AE signal density revealed the presence of pits prior to crack propagation (Figure 11). After a certain exposure time, higher AE activity at specific locations at the steel surface was detected. This was associated with crack initiation. The time before such local increase of AE activity was detected was scattered between replicate experiments. This suggests that initiation is not linked with the accumulation of a certain level of absorbed hydrogen. it is more likely that initiation starts at surface defects. Indeed, initiation can occur after more than 100 hours testing, whereas estimations of hydrogen charging kinetics have shown that a HIC standard massive specimen (X65 grade) is saturated with $\mathrm{H}_{2}$ in about 10 hours in similar experimental conditions [43]. On the contrary to HIC initiation, hydrogen charging time of the material is therefore not the limiting factor for SSC initiation. This explains the importance of surface preparation for SSC specimens. Cernoky et al. [44] demonstrated the importance of specimen surface preparation when tested in acidic $\mathrm{H}_{2} \mathrm{~S}$ media under constant load. The steel specimens exhibited an increasing resistance to SSC when chemically polished compared to mechanical polishing, itself compared to as-machined surface state. According to Cernoky [44], machining was responsible for the existence of a sub-surface strain-hardened zone, at the origin of SSC susceptibility. Another author [45] also observed that cracking hardly initiated on smooth surfaces in the presence of hydrogen. According to this author, a localized corrosion enhancing pitting would promote crack initiation. Indeed, mackinawite scale growth involves the formation of $\mathrm{FeSH}_{\text {ads }}^{-}$which can generate a porous sulfide layer and increase the localized corrosion of the steel [11]. It was reported elsewhere that the formation of such a porous sulfide deposit could retain the pit electrolyte within the pits and propagate pit growth [46]. Moreover, immersion of steel in $\mathrm{H}_{2} \mathrm{~S}$ containing solutions leads to the formation of a rough surface [11]. In the present case, pitting initiation could be enhanced by the presence of $\mathrm{H}_{2} \mathrm{~S}$, as reported for martensitic stainless steel [47], or the presence of a relatively rough surface could constitute occluded cells and play the part of initiating pits in which acidic electrolyte can be retained. 
SSC propagation:

In the present work, the SSC propagation step was defined to start when a significant local increase of AE signals density was detected. Therefore, the duration of crack propagation could easily be calculated, considering the length of the brittle zone of the fracture surface. From the above results, the corresponding duration of SSC propagation was about 30-35 hours in the present experimental conditions. AE data that were detected in the crack area several hours before the final fracture was detected. They exhibited low energy $\left(<10^{2} \mathrm{aJ}\right)$ and low duration $(<1500 \mu \mathrm{s})$, as compared to HIC AE data [39-40]. This could be an indication that SSC propagation involves local plastic strain [4-6], and/or dissolution on the microscale, which is known to be hardly detectable by AE [13][48]. This dissolution mechanism could also account for the difficulties to discriminate SSC AE signals from the signals related to $\mathrm{H}_{2}$ and $\mathrm{FeS}$, since these two last corrosion processes are also closely linked to anodic dissolution. Evaluation of crack propagation rates was obtained from AE data analysis and SEM observations of fracture surfaces. Although times to failure appeared to be scattered (Table 4), propagation rates lie in the range of $2 \times 10^{-8} \pm 0.5 \times 10^{-8} \mathrm{~m} . \mathrm{s}^{-1}$ for all tested specimens. In the literature, SSC propagation rate values have already been evaluated through DCB tests. Ernst et al. measured propagation rates ranging from $10^{-7}$ to $10^{-8} \mathrm{~m} . \mathrm{s}^{-1}$ on a $\mathrm{C} 110$ steel grade in sour media [49]. Szklarz et al. obtained a $10^{-9} \mathrm{~m} \cdot \mathrm{s}^{-1}$ propagation rate in the same conditions for a T95 grade steel [50]. The average propagation rates obtained in the present work from AE are therefore in good agreement with literature results. Yet, it is worth noting that during constant load tests, crack propagation is probably not uniform, as suggested by AE results. Indeed, local high AE signal density tended to decrease until failure (Figures 7 and 10), which could indicate a change in the propagation rate. Interrupted tests before failure would then be helpful to obtain a better understanding of the details of the cracking process. The time when the test has to be interrupted could be determined by AE monitoring.

\section{CONCLUSIONS}

This work was aimed at investigating the different propagation stages of SSC in a low alloy steel in the presence of wet $\mathrm{H}_{2} \mathrm{~S}$, by the use of an acoustic emission technique. The first conclusions of this study concern the acoustic emission technique and its performance for the detection of $\mathrm{H}_{2} \mathrm{~S}$ assisted cracking: 
1. As expected, AE characteristics of SSC exhibits different features from HIC: HIC is associated with high energy AE signals, whereas an emission of low energy signals accompanies SSC propagation.

2. A representation of the density of AE signals $v s$. their location on the gauge length of the specimen and the time of test allows obtaining reproducible, quantitative information on the incubation-initiation time and on the propagation rate.

Initiation and propagation mechanisms were analysed the light of the $\mathrm{AE}$ data recorded during SSC experiments.

3. Initiation of cracks is closely linked to surface preparation of the material. It depends on the presence of defects and/or strain-hardened zone at the surface of the metal. SSC initiation is not related to hydrogen saturation of the steel, but to the formation of a critical pit, associated with a surface defect.

4. The low energy of AE signals indicates that SSC propagation is not the result of subsurface HIC. It is suggested that SSC propagation is the result of a cracking mechanism involving hydrogen embrittlement associated with local plastic strain and/or metal dissolution.

\section{ACKNOWLEDGEMENTS}

The authors would like to thank M. Boinet (Euro-Physical Acoustics), for his help in the analysis of AE data, and G. Parrain for his technical support. H. Marchebois (Vallourec) is also acknowledged for helpful discussions on $\mathrm{H}_{2} \mathrm{~S}$ cracking mechanisms, as well as M. Taylor from PennState University and J.L. Crolet.

\section{REFERENCES}

[1] NACE MR0175/ISO 15156-1, Petroleum and natural gas industries - Materials for use in $\mathrm{H}_{2} \mathrm{~S}$ containing environments in oil and gas production - Part 1: General principles for selection of cracking-resistant materials, International Organization for Standardization, Geneva (Switzerland) (2001)

[2] A. Troiano, Transactions of ASM, 52 (1960) 54-80.

[3] R. Oriani, A decohesion theory for hydrogen-induced crack propagation, in: R. Staehle, J. Hochmann, R. McCright (Eds), Stress corrosion cracking and hydrogen embrittlement of iron base alloy, Houston: NACE, 1977, pp 351-360

[4] C.D. Beachem, Metallurgical Transactions 3 (1972) 437-451 
[5] J. Eastman, T. Matsumoto, N. Narita, F. Heubaum, H.K. Birnaum, Metall. Soc. of AIME, (1981) 397-409

[6] S.P. Lynch, Acta Metallurgica, 36[10] (1988) 2639-2661

[7] J.L. Crolet, La Revue de Métallurgie 101[12] (2004) 1053-1086

[8] S.N. Smith, B. Brown, W. Sun, Corrosion at higher $\mathrm{H}_{2} \mathrm{~S}$ concentrations and moderate temperatures, NACE Corrosion/2011 paper $n^{\circ} 11081$, Houston, Texas (USA) 13-17 March (2011)

[9] D.R. Morris, L.P. Sampaleanu, D.N. Veysey, Journal of Electrochemical Society 127[6] (1980) 1228-1235

[10] J.S. Smith, J.D.A. Miller, British Corrosion Journal 10[3] (1975) 136-143

[11] A. Hernandez-Espejel, M.A. Dominguez-Crespo, R. Cabrera-Sierra, C. RodriguezMeneses, E.M. Arce-Estrada, Corrosion Science 52 (2010) 2258-2267

[12] H. Mazille, R. Rothéa, The use of acoustic emission for the study and monitoring of localized corrosion phenomena, in: K.R. Tretheway, P.R. Roberge (Eds.), Modelling aqueous corrosion, Netherlands, Kluwer Academic, 1994, pp 103-127

[13] S. Yuyama, T. Kishi, Y. Hisamatsu, Journal of Acoustic Emission 2[1/2] (1983) 71-93

[14] W. J. Pollock, D. Hardie, N. J. H. Holroyd, British Corrosion Journal 17 (1982) 103-111

[15] W. W. Gerberich, R. H. Jones, M. A. Friesel, N. Nozue, Materials Science and Engineering 103 (1988) 185-191

[16] F. Ferrer, H. Idrissi, H. Mazille, P. Fleischmann, P. Labeeuw, Wear 231 (1999) 108-115

[17] T.W. Rettig, M.J. Felsen, Corrosion 32 (1976) 121-126

[18] F. Mansfeld, P.J. Stocker, Corrosion 35 (1979) 541-544

[19] A. Arora, Corrosion 40 (1984) 459-465

[20] S. Magaino, A. Kawaguchi, A. Hirata, T. Osaka, Journal of the Electrochemical Society 134 (1987) 2993-2997

[21] R. H. Jones, M. A. Friesel, Corrosion 48[9] (1992) 751-758

[22] H. Mazille, R. Rothea, C. Tronel, Corrosion Science 37[9] (1995) 1365-1375

[23] M. Fregonese, H. Idrissi, H. Mazille, L. Renaud, Y. Cetre, Journal of Materials Science 36 (2001) 557-563.

[24] M. Fregonese, H. Idrissi, H. Mazille, L. Renaud, Y. Cetre, Corrosion Science 43[4] (2001) 627-641

[25] Y.P. Kim, M. Fregonese, H. Mazille, D. Féron, G. Santarini, NDT\&E International 36 (2003) 553-562 
[26] Y.P. Kim, M. Fregonese, H. Mazille, D. Féron, G. Santarini, Corrosion Science 48[12] (2006) 3945-3959

[27] C. Jomdecha, A. Prateepasen, P. Kaewtrakulpong, NDT\&E International 40 (2007) 584593

[28] F. Bellanger, H. Mazille, H. Idrissi, NDT\&E International 35 (2002) 385-392

[29] K.H.W. Seah, K.B. Lim, C.H. Chew, S.H. Teoh, Corrosion Science 34 (1993) 1707-1713

[30] L. Jaubert, M. Fregonese, D. Caron, F. Ferrer, C. Franck, E. Gravy, P. Labeeuw, H. Mazille, L.Renaud, Insight 47[8] (2005) 465-471

[31] C.C. Weng, R.T. Chen, Journal of the Chinese Institute of Engineers, 16[2] (1993) 195202

[32] M.S.Cayard, R.D.Kane, Evaluation of various methods of reducing the duration of SSC qualification testing, NACE Corrosion/97 paper $n^{\circ} 97057$, New-Orleans, Louisiana (USA), 9$14 \operatorname{March}(1997)$.

[33] A.D.B.Gingell, X.Garat, Observations of damage modes as a function of microstructure during NACE TM0177-96 tensile testing of API 5L grade X60 linepipe steels, NACE Corrosion/99 paper $n^{\circ}$ 99600, San Antonio, Texas (USA), 25-30 April (1999).

[34] C-C. Weng, R-T. Chen, Journal of Chinese Institute of Engineers, 16[4] (1993) 489-498

[35] S.Y. Tsai et H.C. Shih, Journal of the Electrochemical Society, 145[6] (1998) 1968-1976

[36] S. Amami, P. Marchand, S. Duval, X. Longaygue, M. Fregonese, H. Mazille, J.P. Millet, Detection by acoustic emission technique of the corrosion stress cracking within steel structures in $\mathrm{H}_{2} \mathrm{~S}$ containing mediums, EFC Eurocorr/2003, Budapest (Hungary), 28 September - 2 October (2003).

[37] NACE TM0284-2003, Evaluation of pipeline and pressure vessel steels for resistance to hydrogen-induced cracking, NACE International, Houston, TX (USA) (2003).

[38] NACE TM0177-96, Laboratory testing of metals for resistance to specific forms of environmental cracking in $\mathrm{H}_{2} \mathrm{~S}$ environments, NACE International, Houston, Texas (USA) (1996).

[39] V. Smanio, M. Fregonese, J. Kittel, T. Cassagne, F. Ropital, B. Normand, Journal of Materials Science, 45[20] (2010) 5534-5542

[40] V. Smanio, J. Kittel, M. Fregonese, T. Cassagne, F. Ropital, B. Normand, Corrosion, in press

[41] J. Galland, J. Sojka, M. Jerome, Introduction d'hydrogène dans les aciers. $1^{\text {ère }}$ partie : Rôle de paramètres physicochimique et métallurgiques sur la fragilisation par l'hydrogène, in: B. Normand, N. Pébère, C. Richard, M. Wery (Eds.), Prévention et lutte contre la corrosion : 
une approche scientifique et technique. Presses Polytechniques et Universitaires Romandes, Lausanne (2004), 311-319

[42] EFC publication $n^{\circ} 16$, Guidelines on materials requirements for carbon and low alloy steels for $\mathrm{H}_{2} \mathrm{~S}$-containing environments in Oil and Gas production, The Institute of Materials, London (UK) (1995).

[43] J. Kittel, V. Smanio, M. Fregonese, L. Garnier, X. Lefebvre, Corrosion Science, 52[4] (2010) 1386-1392

[44] E.P. Cernoky, D.L. Sponseller, T .E. Sponseller, Unconventional applications of Nace method-a tests to investigate and characterize fundamental aspects of low alloy steel in $\mathrm{H}_{2} \mathrm{~S}$ environments, NACE Corrosion/2006 paper $n^{\circ} 129$, San Diego, California (USA) 12-15 March (2006)

[45] D. Le Friant, PhD thesis, Ecole Nationale Supérieure des Mines de Saint Etienne, France, 2000 .

[46] U.M. Dawoud, S.F. Vanweele, Z. Szklarska-Smialowska, Corrosion Science 33[2] (1992) 295-30

[47] M. Saenz de Santa Maria, A. Turnbull, Corrosion Science 29[1] (1989) 69-88

[48] P. MacIntyre, G. Green, British Journal of Non-Destructive Testing, 20[3] (1978) 175140

[49] H.A. Ernst, J. Villasante, N. Pachao, D. Johnson, Specimen geometry effects on crack growth in sour environments, NACE Corrosion/2002, paper , $\mathrm{n}^{\circ} 02060$, Denver, Colorado (USA) 7-14 April (2002).

[50] K.E. Szklarz, Understanding the size effect in NACE TM0177 method D (DCB) testing and implications for users, NACE Corrosion/2001 paper $n^{\circ} 01074$, Houston, Texas (USA) 1116 March (2001). 
Tables

Table 1. Chemical composition (wt \%) of C110 steel.

\begin{tabular}{cccccccccc}
\hline $\mathbf{C}$ & $\mathbf{M n}$ & $\mathbf{S i}$ & $\mathbf{P}$ & $\mathbf{S}$ & $\mathbf{C r}$ & $\mathbf{N i}$ & $\mathbf{M o}$ & $\mathbf{C u}$ & $\mathbf{N b}$ \\
\hline 0,309 & 0,394 & 0,343 & 0,015 & 0,002 & 0,964 & 0,037 & 0,834 & 0,018 & 0,033 \\
\hline
\end{tabular}

Table 2. Mechanical tensile properties of C110 steel (tests conducted according to EN10002-1 standard) (YS: Yield Strength, UTS: Ultimate Tensile Strength, El: Elongation)

\begin{tabular}{ccc}
\hline YS(MPa) & UTS (MPa) & EI\% \\
\hline 798 & 887 & 20 \\
\hline
\end{tabular}

Table 3. Experimental conditions and corresponding times to failure.

\begin{tabular}{llllll}
\hline $\begin{array}{l}\text { Experimental } \\
\text { Conditions }\end{array}$ & $\mathrm{pH}$ & $\mathrm{pH}_{2} \mathrm{~S}$ (bar) & $\begin{array}{l}\text { Applied load } \\
(\% \mathrm{YS})\end{array}$ & $\begin{array}{l}\text { Surface } \\
\text { preparation }\end{array}$ & Time to failure \\
\hline 1 & 3,5 & 1 & 0 & $\begin{array}{l}\text { Mechanical } \\
\text { polishing }\end{array}$ & $\begin{array}{l}\text { No failure } \\
\text { No HIC cracks }\end{array}$ \\
\hline 2 & 3,5 & 1 & 90 & $\begin{array}{l}\text { Chemical } \\
\text { polishing }\end{array}$ & $\begin{array}{l}\text { No failure } \\
(800 \mathrm{~h})\end{array}$ \\
\hline 3 & 3,5 & 1 & 90 & $\begin{array}{l}\text { Mechanical } \\
\text { polishing }\end{array}$ & {$[64-200 \mathrm{~h}]$} \\
\hline
\end{tabular}

Table 4. Cracks incubation time, propagation time and propagation rates

\begin{tabular}{|l|l|l|l|}
\hline Test \# & Time to failure $(\mathrm{h})$ & Incubation time $(\mathrm{h})$ & $\begin{array}{l}\text { Propagation time } \\
(\mathrm{h})\end{array}$ \\
\hline 1 & 132 & 99 & 33 \\
\hline 2 & 140 & 104 & 36 \\
\hline 3 & 90 & 60 & 30 \\
\hline 4 & 113 & 85 & 28 \\
\hline 5 & 200 & 121 & 79 \\
\hline 6 & 64 & 5 & 59 \\
\hline 7 & 116 & 83 & 34 \\
\hline
\end{tabular}


Figure 1. Correlation chart representing absolute energy as a function of signals duration for a test conducted in the EFC 16 solution at $\mathrm{pH} 4.5$ under 1 bar $\mathrm{H}_{2} \mathrm{~S}$, on a X65 SwS specimen [33].

Figure 2. Experimental device.

Figure 3. Correlation chart representing absolute energy as a function of signals duration for a test conducted in the EFC 16 solution at $\mathrm{pH} 3.5$ under 1 bar $\mathrm{H}_{2} \mathrm{~S}$ (a) on a C110 specimen without applied load - (b) with an applied stress of $90 \%$ YS on a C110 chemically polished specimen - (c) with an applied stress of $90 \%$ YS on a C110 standard polished specimen

Figure 4. (a) Fracture surface of $\mathrm{C} 110$ steel tested in the EFC 16 solution at $\mathrm{pH}$ 3.5 under 1 bar $\mathrm{H}_{2} \mathrm{~S}$ with an applied stress of $90 \% \mathrm{YS}-(\mathrm{b})$ Profile of the fracture surface (red line on figure $5 a$ ).

Figure 5. Detail of the brittle area (1) of C110 fracture surface.

Figure 6. Detail of the ductile area (2) of C110 fracture surface.

Figure 7. Density representation of the location of all the AE signals in function of time (C110 steel, $\mathrm{pH} 3.5,1$ bar $\mathrm{H}_{2} \mathrm{~S}, \sigma=90 \%$ YS).

Figure 8. SEM observation of the area identified by a circle on the figure 10.

Figure 9. Amplitude of AE signals vs. their location on the gauge length of the specimen: identification of AE signals located on the final rupture area of the gauge length (zone 1 - $x$ between 6.7 and $7.0 \mathrm{~cm}$ reported from the position of the sensor located at the bottom of the specimen) and $A E$ signals located just above the final rupture area, where no crack neither no increase in $A E$ signals density were detected (zone 2 - $x$ between 6.3 and $6.6 \mathrm{~cm}$ ).

Figure 10. (a) Number and (b) cumulative energy of AE signals vs. time of test for zones 1 and 2.

Figure 11. Cross section observations of high $A E$ density areas. 


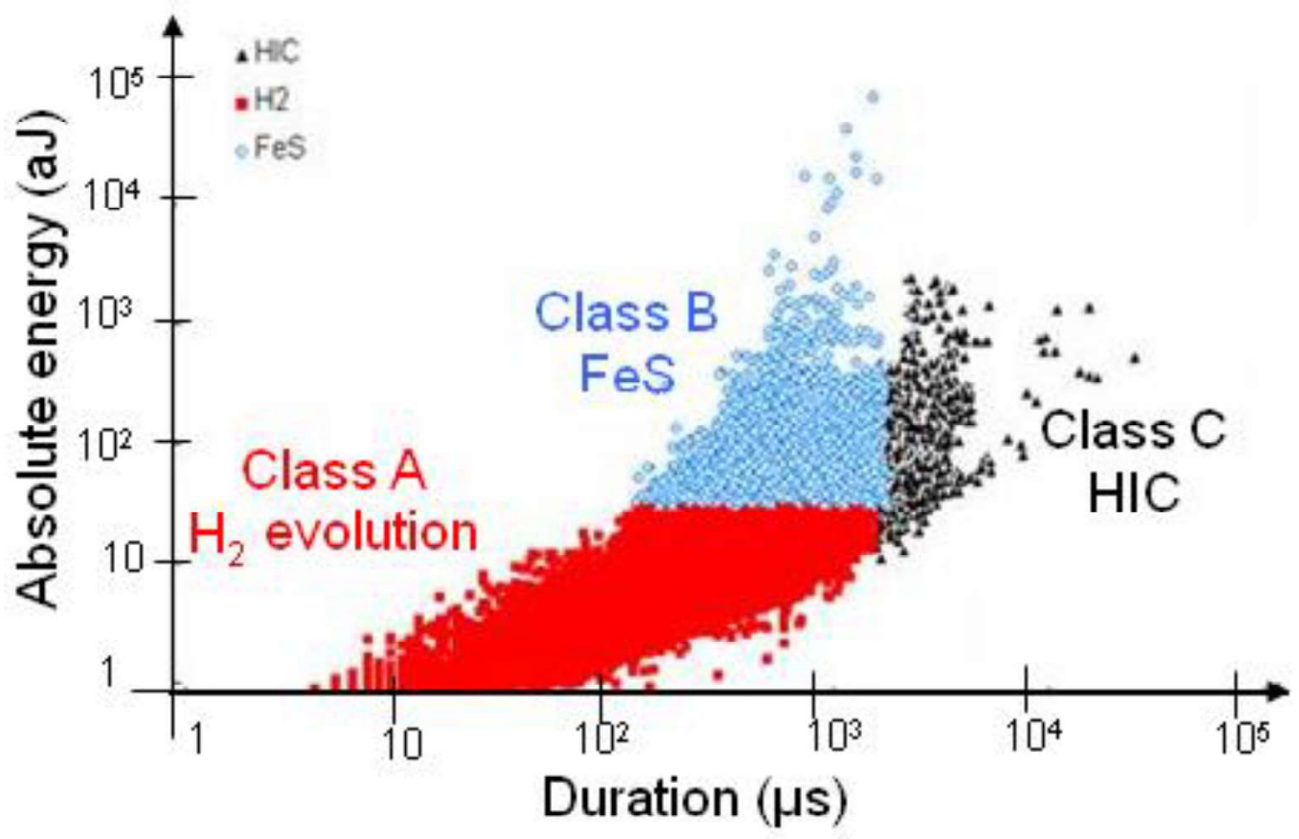

Fig.1 


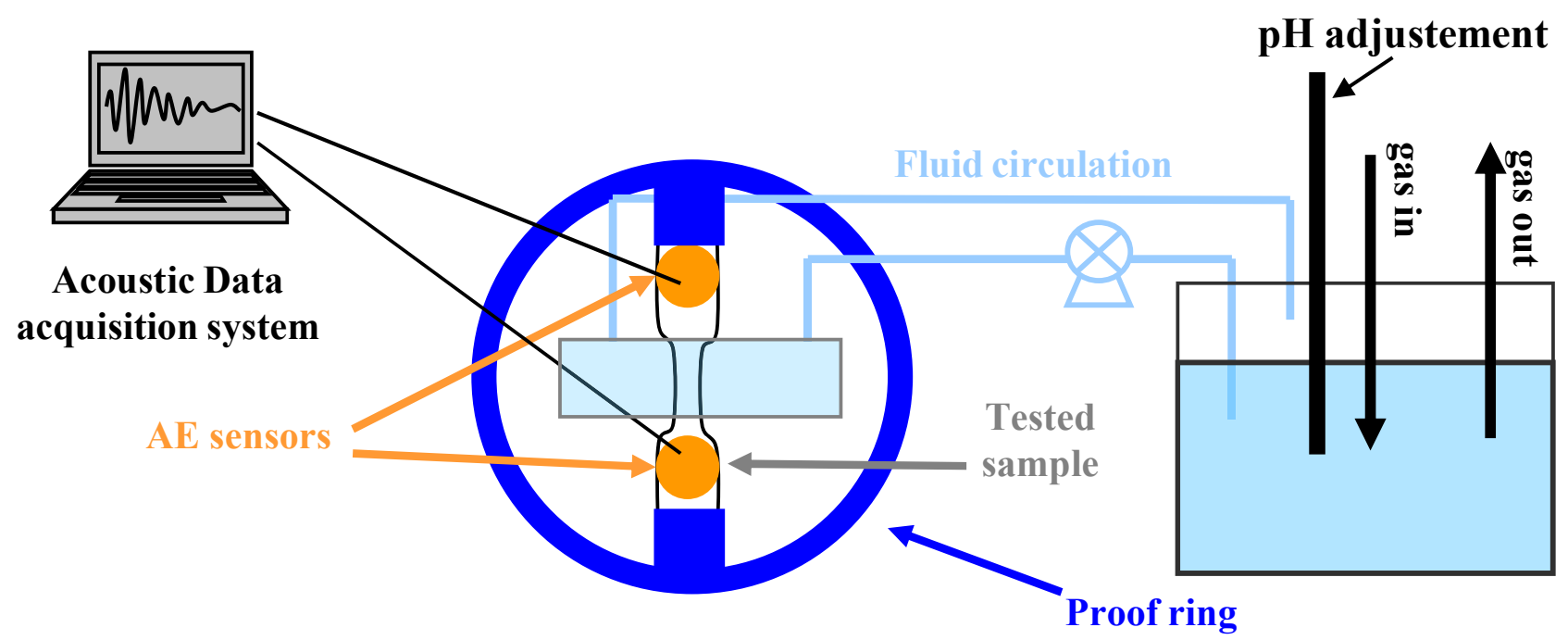

Fig.2 


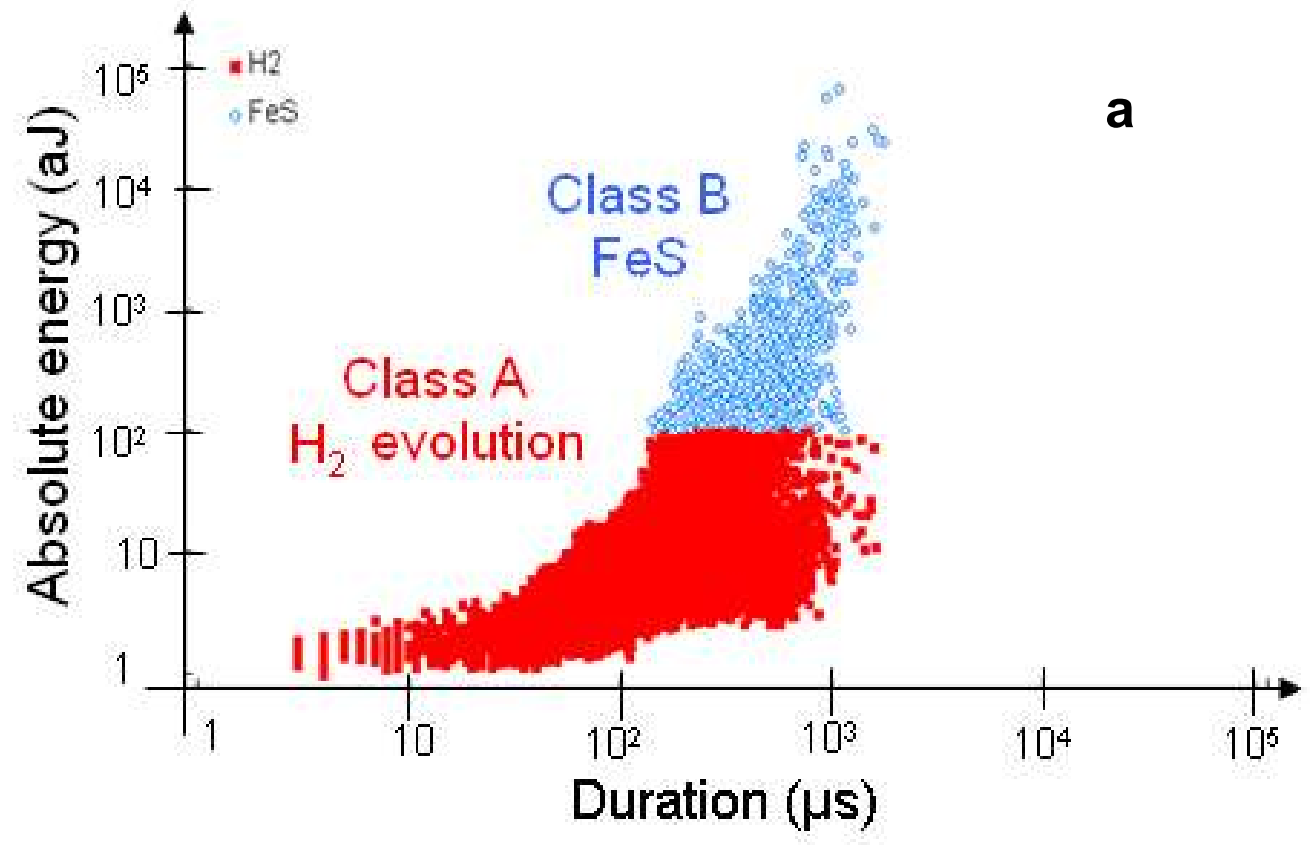

Fig.3a 


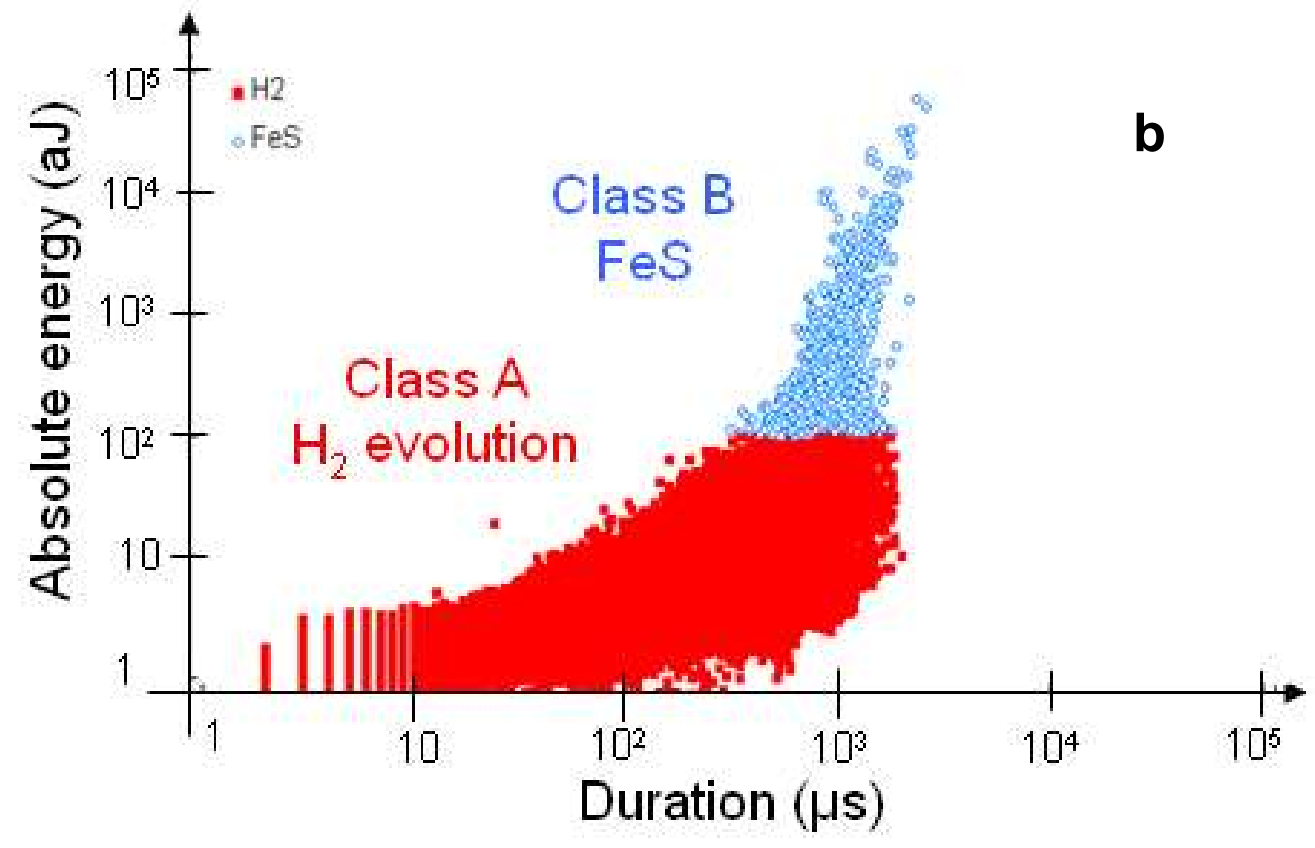

Fig.3b 


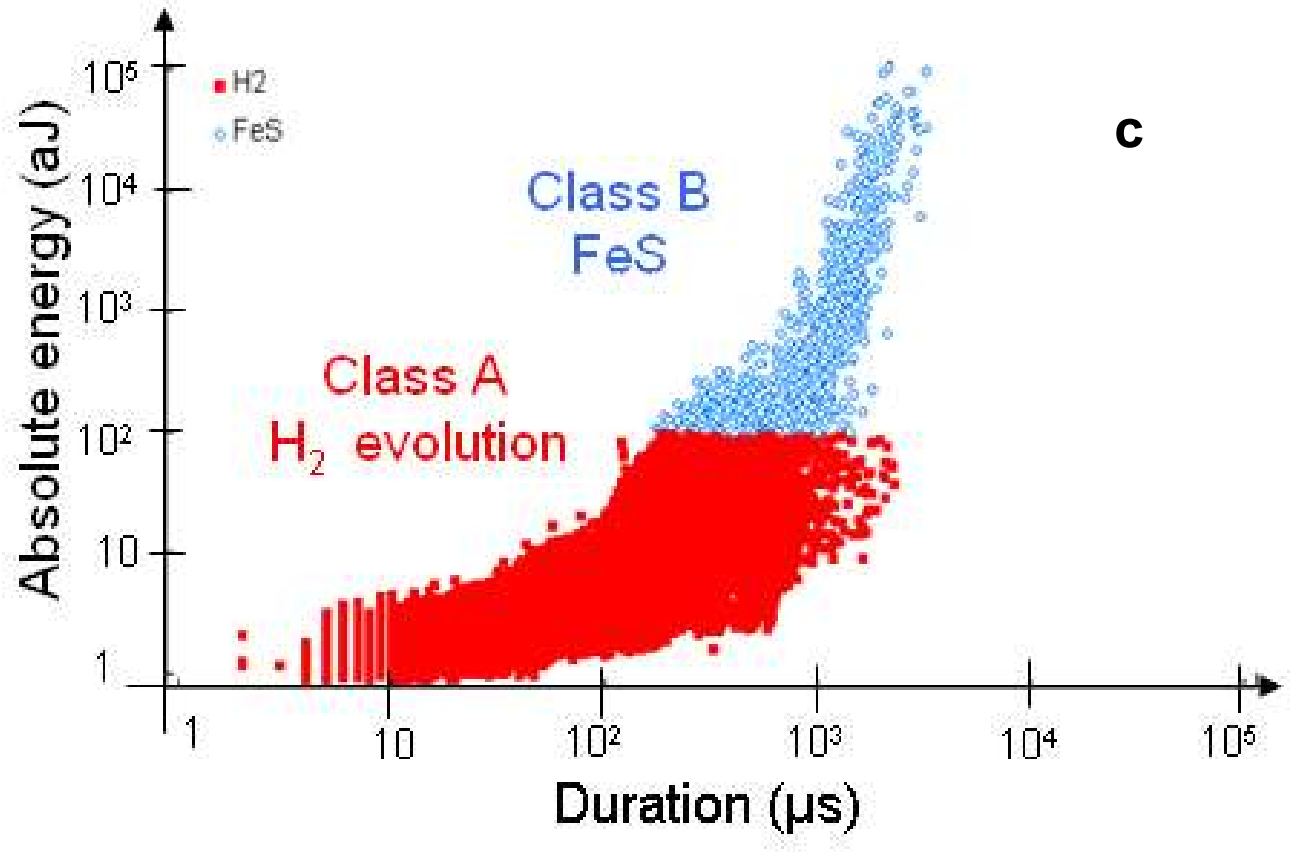

Fig.3c 

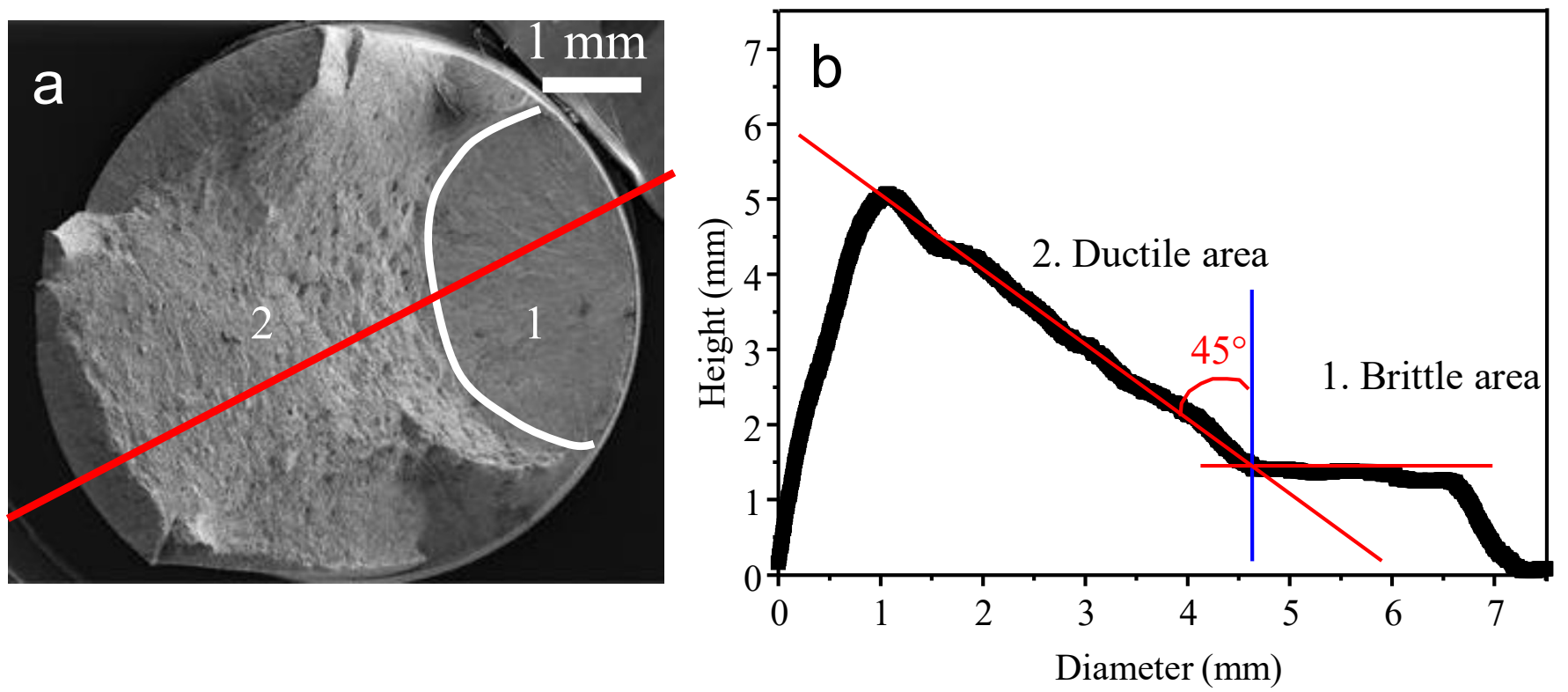

Fig.4 


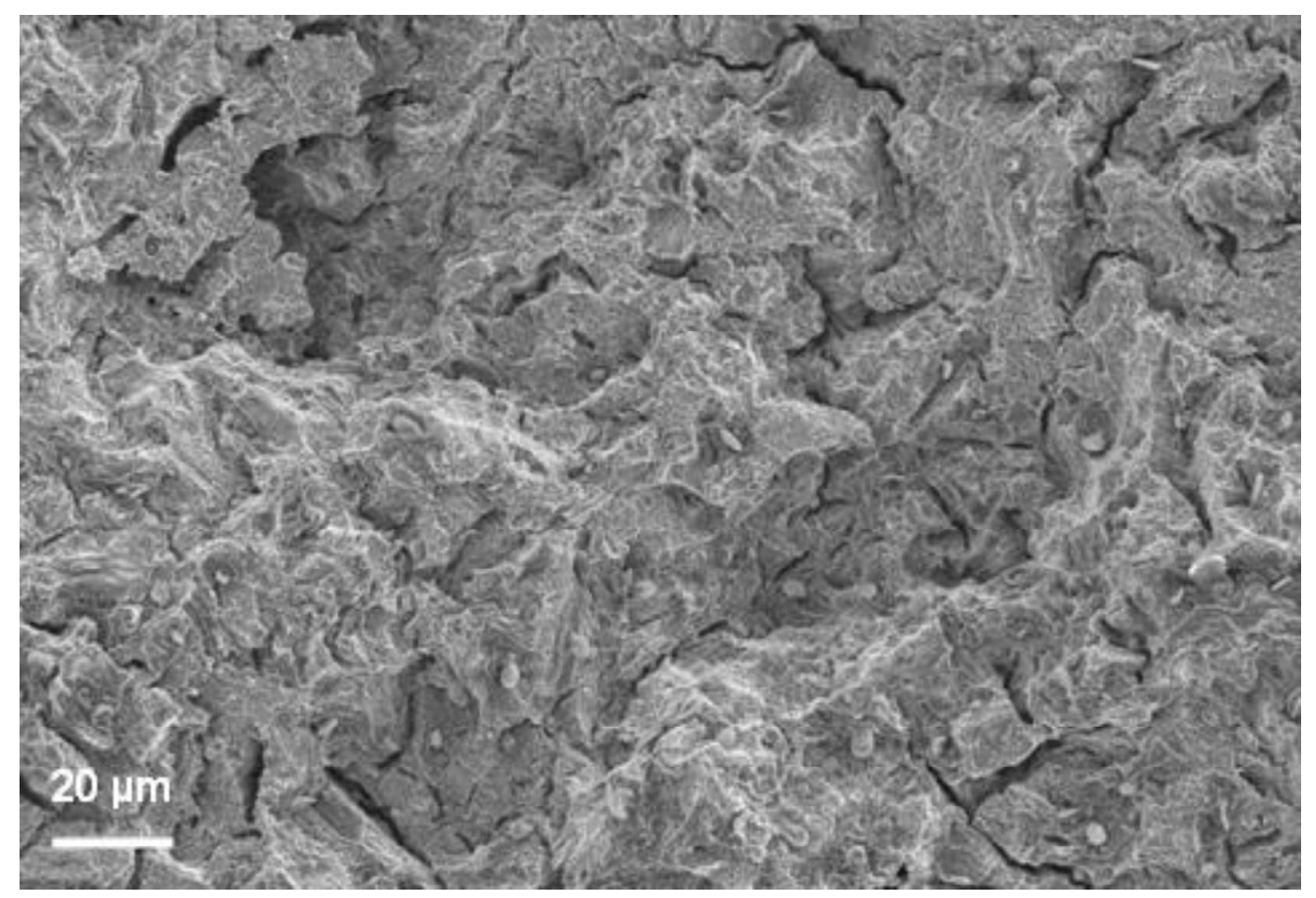

Fig.5 


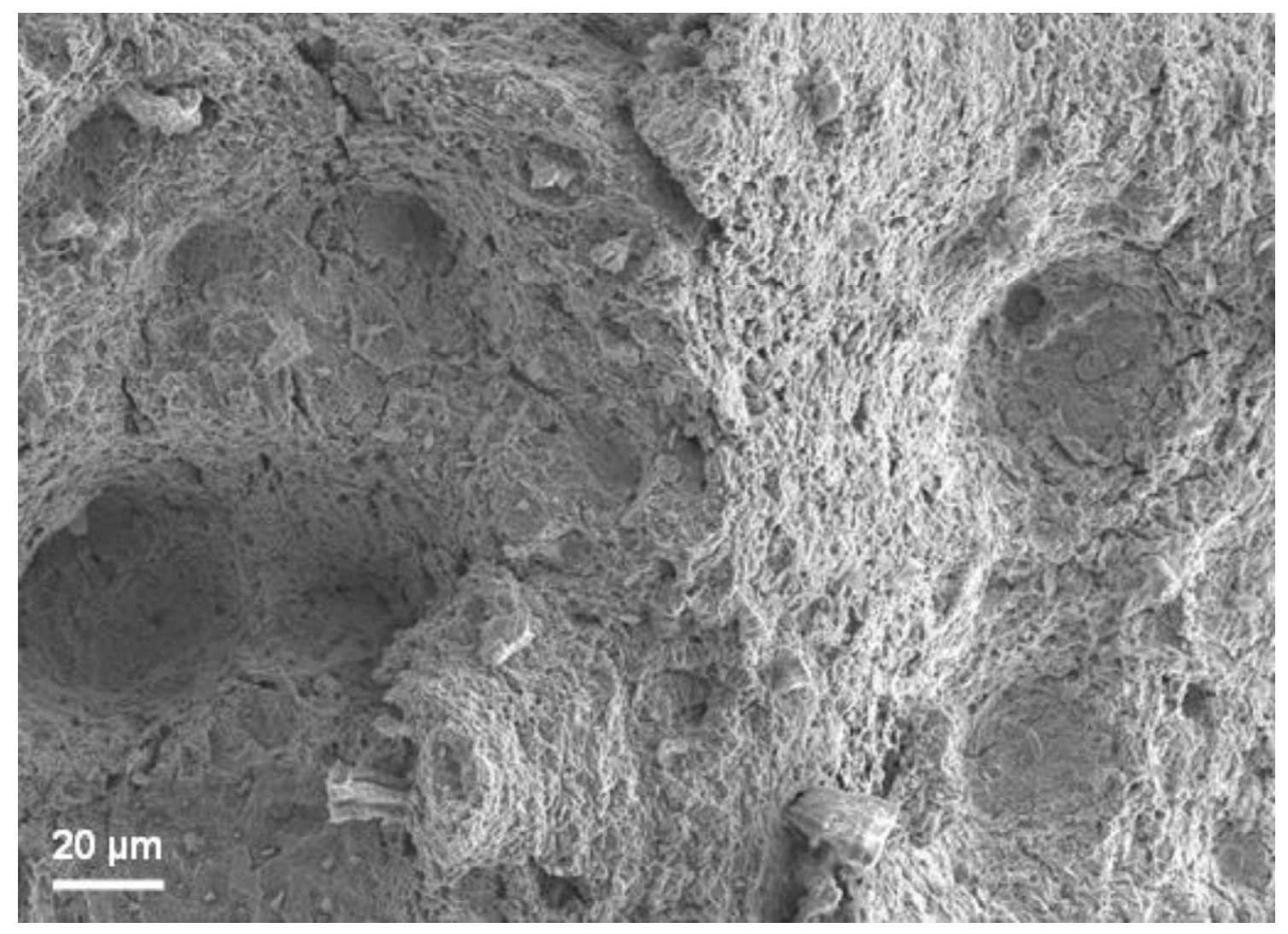

Fig.6 


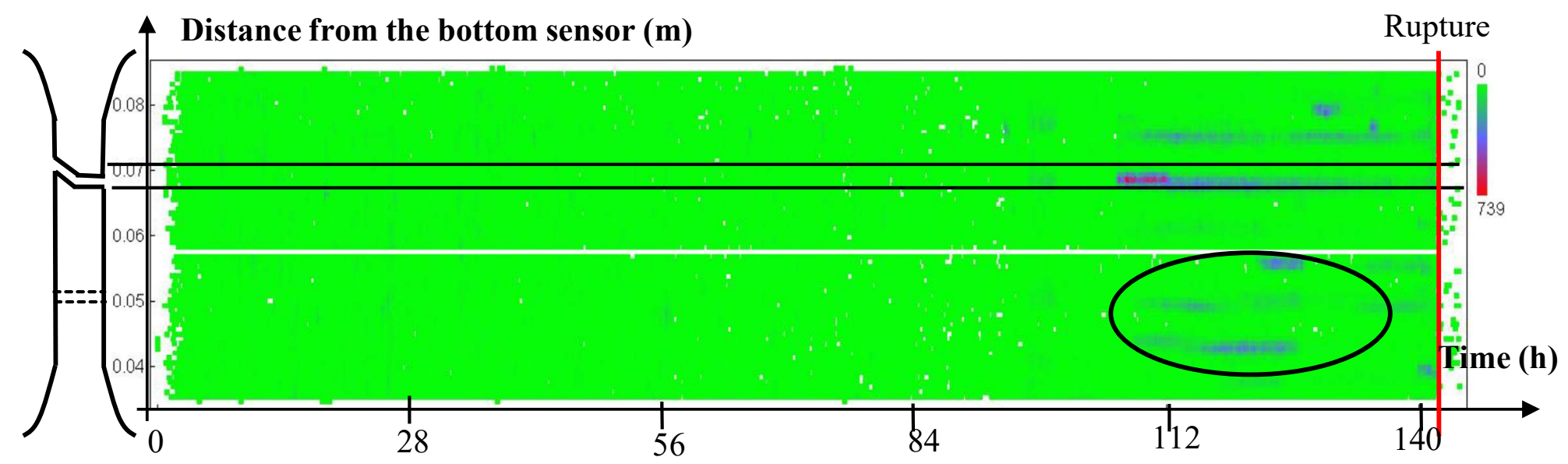

Fig.7 


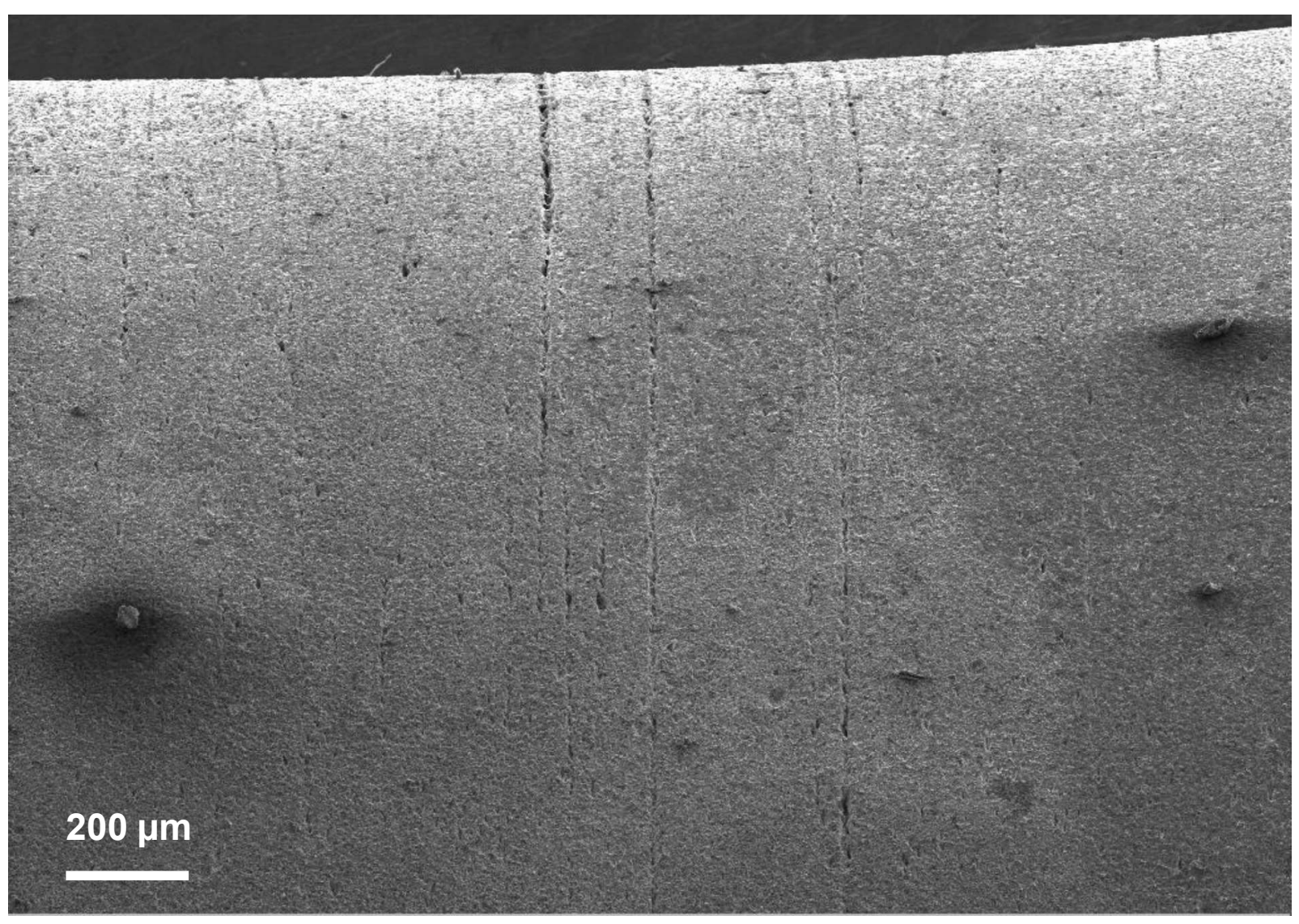

Fig.8 


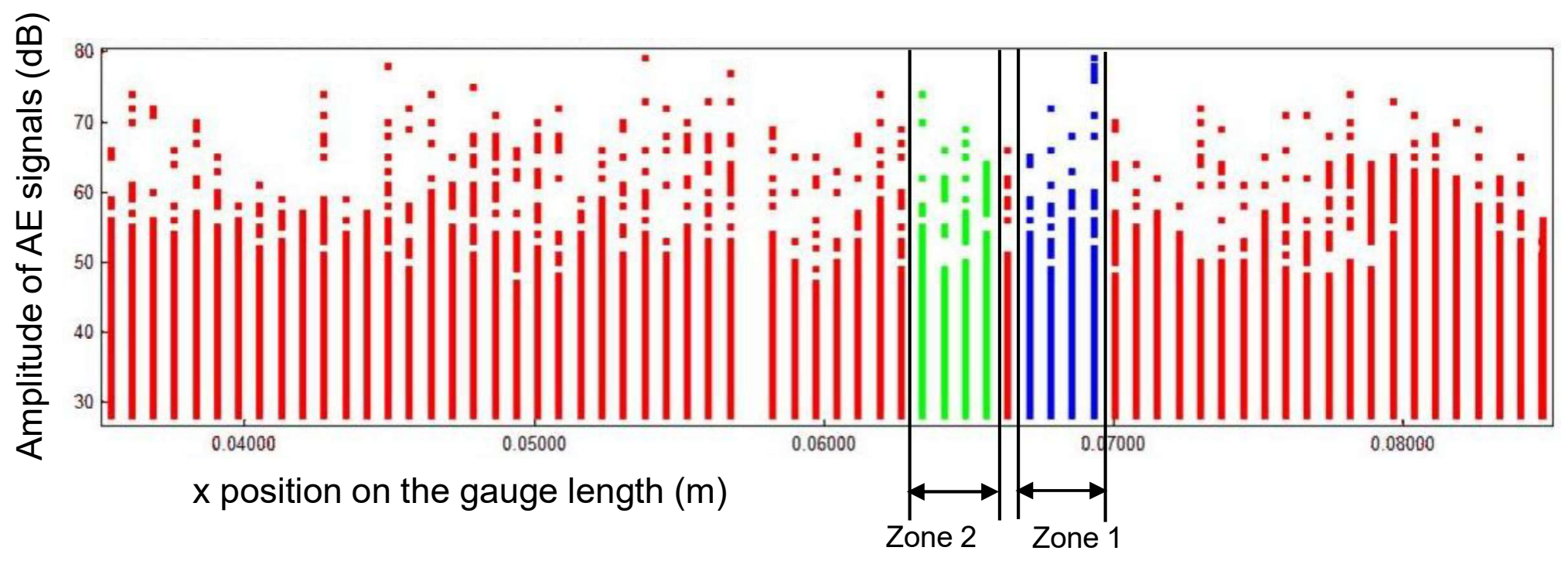

Fig.9 

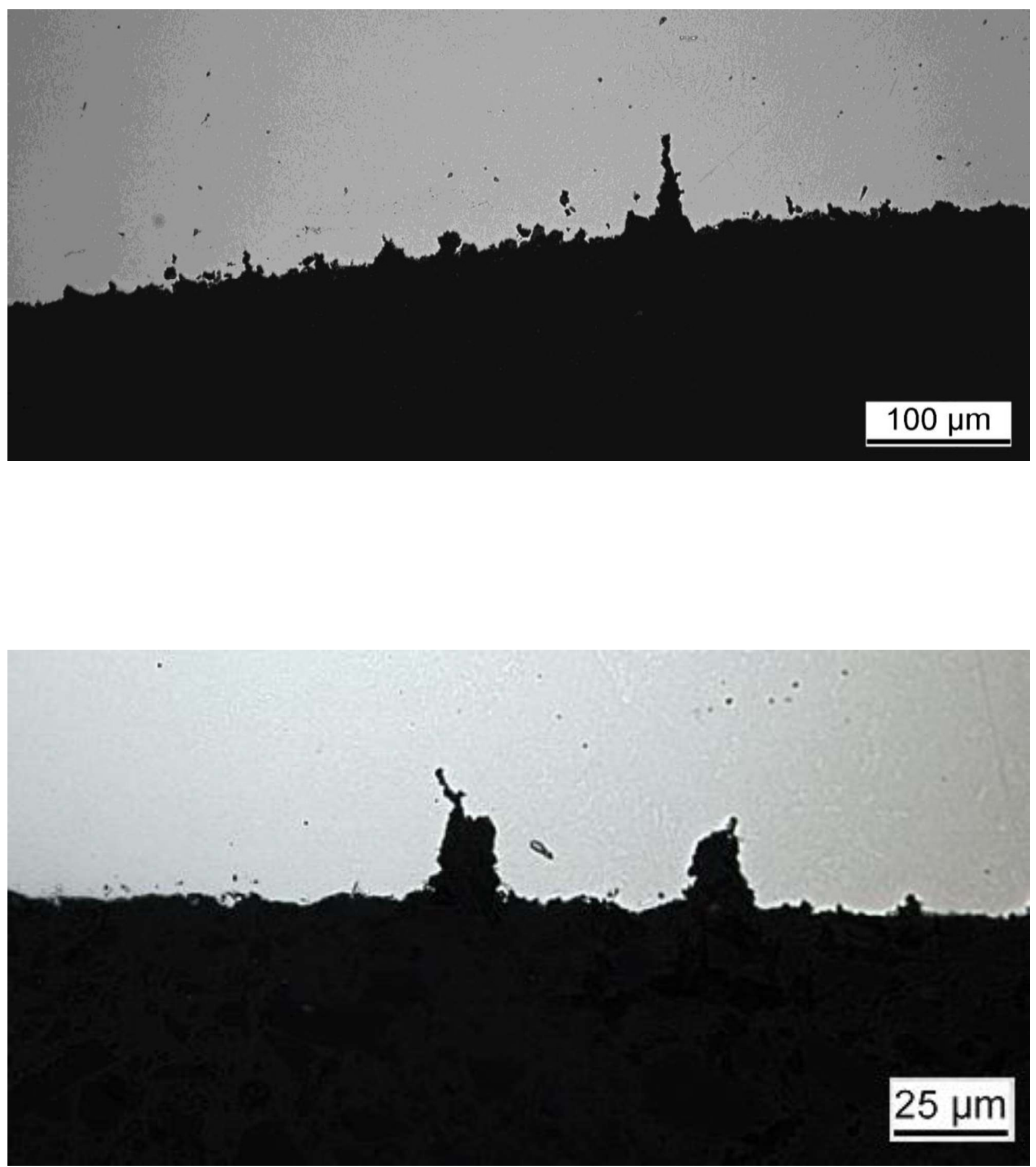

Fig.11 